\title{
The Role of Transformational Leadership - Between Challenges and Opportunities - in Applying the Comprehensive Quality at Al-Istiqlal University in Palestine as a Case Study
}

\author{
Mohammed Halaseh \\ Scientific Research and Graduate Studies, Al-Istiqlal University, PO box 10, Jericho, Palestine
}

\begin{abstract}
The study aimed to identify the Role of Transformational Leadership - between Challenges and Opportunities in Applying the Comprehensive Quality at Al-Istiqlal University in Palestine as a case study. To conduct the study the researcher used the descriptive method and relied on the sources of his data on the previous references and studies in addition to the information available at Al-Istiqlal University. The study examined the extent of applying the comprehensive quality through the academic, administrative and infrastructure fields. The study reached several results; some of them are listed below:

1-Al-Istiqlal University is applying the quality in the field of planning since its inception. It is strategic and operational plans are constantly being updated. The University has evaluated itself (according to the standards and weights guide for quantitative and qualitative indicators of quality assurance and accreditation according to the guide of Arab universities that are members in the union issued in Amman, 2010). It works to evaluate deviations.

2- The University administration holds periodic meetings with the staff to discuss and evaluate the conditions of the University, exchange viewpoints, and suggestions for continuous improvement and development.

3- The University does not have most of its curriculum. The number of faculty members who hold the rank of professor and associate professor is limited compared to the number of teaching staff. The participation of students in the evaluation of curricula, teachers and study plans is not active.

4- The University does not benefit from clean (solar) energy enough. It also does not benefit from fertile agriculture land it owns, and it does not treat sewage water.

5- The number of research papers by teaching staff and students published in refereed international journals is not at the required level.

Based on the results of the study, the researcher made the following recommendations:

1-Providing special curricula for the University, giving scientific research more attention, opening promotions for scientific ranks, and the need to focus on the participation of students in evaluating curricula, teachers and study plans.

2- The University must take advantage of clean (solar) energy in the generation of electricity for self-use. as well as the exploitation of fertile agricultural land to grow vegetables and fruits to meet the University needs, and sewage treatment for irrigation.
\end{abstract}

Keywords: Transformational Leadership, Challenges, and Opportunities, comprehensive quality, Al-Istiqlal University.

DOI: $10.7176 /$ EJBM/11-36-11

Publication date: December $31^{\text {st }} 2019$

\section{Introduction}

This age has witnessed lots of developments and rapid changes because of the evolution of communication technology and the information revolution. This made the organizations suffer from challenges in how to keep up with the changes and ways to adapt to them. Therefore, it required finding modern ways to replace traditional ways and procedures in management and leadership as well as providing an appropriate and flexible means to respond to these challenges, and this made the current organizations think seriously of finding more efficient leaders and more convenient adapted with this age away from the old leadership ways.

These rapid changes forced the management of these organizations to speak in one language if they wanted to remain and hold their market position, and that language is the language of this age, which is the language of change and making radical changes in their administrative methods and looking for more creative and new ways. This will happen by focusing on the human element who is the essence of the administrative process, by creating the appropriate administrative environment.

Based on the above, these rapid changes are normal in the process of development and scientific progress in different areas of life, especially in the higher educational organizations (universities).However, the difficulties of keeping up with these changes is not only faced by Al-Istiqlal University but also by international universities. Add to that the fact that this University was created in Palestine under occupation, which is a challenge in the development of the University in different areas especially in the field of applying comprehensive quality. 
Despite that, using the transformational leadership to apply the comprehensive quality in leading and managing the University is a chance and an important motive to improve and develop the University leadership in the field of applying the comprehensive quality.

This research (study) aims to find out the role of transformational leadership in applying the principles of comprehensive quantity management in Al-Istiqlal University through what the University faces of challenges (obstacles) and how to overcome these challenges by the opportunities that can be used.

This research (study) has four topics. The first topic is for the research methodology (study). The second topic is for the theoretical framework and previous studies. The third topic is for answering the study questions, and the fourth topic is for showing results and recommendations.

\section{Research plan (study):}

\subsection{The research methodology}

2.1.1 The study problem:

Al-Istiqlal University faces lots of difficulties and obstacles, as it is a University under occupation. Not only that but as it is a university that was established to supply the Palestinian security services with academically trained and qualified staff, despite that and to overcome these difficulties and obstacles related to changes, technological developments and the accelerated information revolution, as the obstacles forced by the Israeli occupation. Despite all the above, the University has lots of opportunities and available possibilities in applying comprehensive quality to overcome these challenges and obstacles through using modern leadership theories (transformational leadership). As said, we can frame the study problem through the main question "What is the role of transformational leadership in applying comprehensive quality principles? " Derived from this question the following sub-questions:

1. Does the University leadership has transformational leadership attributes?

2. What is the extent applying of comprehensive quality principles in Al-Istiqlal University exist?

3. What are the obstacles facing the applying of comprehensive quality principles in the University?

4. What are the available opportunities before the transformational leadership in the University to overcome the obstacles?

2.1.2 The Study Approach:

The researcher used the descriptive method which is the most appropriate for this study.

The Study Population: Management, academic and military staff at Al-Istiqlal University - Palestine.

The Study Resources: It relied on books, references, researches, studies related to the subject of this study and the information collected from Al-Istiqlal University.

2.1.3 The Significance of the Study:

The significance of this research comes from the fact that it is the first research - according to the researcher knowledge - that studies the role of transformational leadership in the application of the principles of comprehensive quality at Al-Istiqlal University, as it is an entrepreneurial University on the national level. The first and sole University which combines' military security and police sciences with academic sciences, as it grants Bachelor degree in many disciplines for students who wish to join the Palestinian security services. It also grants the Master's degree in the General Administration for the civilians and the military. Therefore, for the necessity of the sustainability of the University regarding the difficulties and obstacles that the University faces, it must shift to the new leadership methods to overcome the difficulties and benefit from the available opportunities in applying comprehensive quality field. Based on the above we can sum up the importance of this study in the following points:

1. The transformational leadership is considered one of the up-to-dated theories in the leadership field. Therefore, we must benefit from its features in developing the strategic choices available in the comprehensive quality.

2. The comprehensive quality is considered one of the requirements of this age to maintain competitiveness and sustainability.

3. It clarifies obstacles and the extent of accessibility of available opportunities to improve and develop.

\subsection{The Objectives of the Study:}

This study aimed to identify the relationship between the variables (the role of transformational leadership, applying the principle of comprehensive quality) by mentioning the obstacles and difficulties facing the University and available opportunities for enhancement to achieve these sub aims:

1. To show the important role of transformational leadership in enhancing the leaders' possibilities in how to respond to changes in the internal and external environment.

2. To highlight the principles and concepts of transformational leadership and its importance in applying the principles of comprehensive quality.

3. To know to what extent does the University apply comprehensive quality. 
4. To examine the difficulties and obstacles facing the University when applying comprehensive quality.

5. To know what are the chance and opportunities available to enhance the teaching and administrative environment at the University.

\subsection{The Study limitations:}

1. Spatial limit: Al-Istiqlal University - Palestine

2. Time limit: the School year $2018-2019$

3. Objective limit: The role of transformational leadership between challenges and opportunities in applying the principles of comprehensive quality.

\subsection{The Study Terminology:}

The transformational leadership: The transformational and procedural term became a foundation in studying leadership and was mainly used to differentiate between management and leadership. Burns, 1978 to differentiate between leaders who build motivational goal relationships with their subordinates and leaders who extensively depend on benefit exchange to get results, created the transformational leadership. Burns,1978 identified transformational leadership as following " it's a procedure where the leader and followers seek to promote each other to achieve the highest level of motivation and morality". The transformational leadership seeks to promote the subordinate's feelings through adapting ideas and moralities such as freedom, justice, equality, peace, and humanity. The attitude of transformational leadership starts from the leader's values and personal beliefs and not from the benefits exchange with subordinates (Bass,1985).

Comprehensive Quality: comprehensive quality is one of the most intellectual and philosophical concepts that has been a concern of many specialists, researchers, administrators and academics who especially want to improve and enhance the product and service performance in different organizations. The Japanese administration played a key role in this field as it dominated by presenting different goods with high quality and reasonable cost. This led to success by counting on quality control loops and using the comprehensive quality management. (Al Shamaa \&Hammoud, 2000).

Al- Istiqlal University: The Palestinian Academy for Security Sciences was founded in 1998 in Jericho Palestine. In 2011, it was transformed into a University by presidential resolution, and the legal proceedings have been completed by the issuance of the law article number 10 for the year 2013. It is the first and the newest only State University that specializes in higher education in security, military and police sciences, so that it is an essential tributary for the Palestinian Security institution that provides it with security cadres holding academic specializations. That is achieved through three colleges providing (9) Bachelor's programs and one Mater's program in (General Administration), in addition to a Diploma college that provides three programs, as well asTraining and Development Institute that provides (5) professional Diploma programs in the security fields. (Complementary Strategic plan 2017 - 2020 ) for Al- Istiqlal University.

\section{The Theoretical Framework and Previous Studies}

\subsection{The Theoretical Framework:}

\subsubsection{The Transformational Leadership}

The latest developments in the leadership theories have changed the interest in the early charismatic leadership theory that considered the leader an exceptional and unusual person, and the staff as people relying on the leader in the newest charisma theory or the transformational leadership which depends on the consensus and the social characteristics and not only on the personal characteristics. It also helps the staff to develop and enhance their performance independently, therefore, the leader who has the charismatic characteristics becomes a transformational leadership. Transformational leadership is the deepest and comprehensive indication of the charismatic leadership (Gulab, 2011, p.510)

3.1.1.1 The Importance of Transformational Leadership:

It is common sense that leadership - generally and transformational leadership in particular - has a major role in making organizational changes to achieve aims through the leader's pursuit for his subordinates progress for achieving self - development and working on the staff development in order to raise the performance of the organization as a whole. (Sani \& Maharani. 2012: 102). The transformational leadership has taken over the researchers' interest since the $1980 \mathrm{~s}$, and it still has fame in the modern leadership approaches. Most management researchers agreed on several factors which helped this theory to have more power and importance to outperform other management theories. They are summed up in the following points (Issawi, 2008, p. 112) :

1. The transformational leadership seeks to delegate important powers in management to empower individuals, develop their skills and enhance their self - confidence.

2. The transformational leadership characters can be reinforced by training and practicing which is reflected positively on the performance of the subordinate on various levels of the organization.

3. The transformational leadership adopts the idea of (ethical responsibility) which leads to motivating 
creativity and innovation. It also encourages to exceed the personal benefit in favor of the public interest.

4. The transformational leadership is characterized as being able to face different situations and that helped in making it valid for application in different organizations and at every organizational level.

3.1.1.2. The Principles of Transformational Leadership:

They are summed up in the following points (Katzenbach, 2005, p.131):

1. To see the organization as a system that has several interconnected and reactive elements.

2. To work on framing the strategic plan including vision, mission, and goals with the help of the organization staff.

3. To find an accessible administrative system to avoid traditional management complications that help in establishing trust with the workers and motivate them for hard work to achieve the organization's goals.

4. To have an interest in building the workers' capacity through sustainable training programs.

5. To empower individuals through delegation of powers individually or for staff without affecting the cohesion of the institution.

3.1.1.3 Requirements for Building Transformational Leadership:

when building transformational leadership, we have to achieve several requirements to achieve the organization goals. These requirements include the following (Mohammad, 2010, p.56):

1. A clear vision for the future of the organization.

2. To understand the group dynamics and the nature of the organization to know how to deal with others in the organization.

3. To understand the requirements of globalization and adjust with it avoiding the negative effects on the principles and values of the organization.

4. To reinforce the evolution and self - development of the organization.

5. To give interest in the staff in the organization - as they are the foundation - and to encourage the integrative culture between them.

3.1.1.4. The characteristics of the transformational leadership:

Writers and researchers had different points of view about the features of the transformational leader, but most of them agreed on five important characteristics and they are (Bernouti, 2010, p.46):

1. Perfect effect (charisma): Having this feature means that the transformational leader is a row model for subordinates in regards to moralities and functional values (Niekerk, 2005, p.5).

2. Motivational inspiration: Leaders have to act according to this characteristic in ways to motivate and inspire subordinates and that's through overriding public interest and reinforcing connectivity between them, which make them focus on future conditions and motivate them to examine different alternatives (Al - Ghamdi, 2001, p.8). This characteristic indicates that the leader is capable of attractive expression, raising the subordinates' motives and spreading enthusiasm among them (Goodwin et al, 2011, p.411). In this field ( $\mathrm{Al}$ - Gazali )indicates that subordinates' motivation depends on the behavior of the transformational leader which makes the subordinate more challenged and stir up their feelings ( $\mathrm{Al}-$ Gazali, 2012, p.9).

3. Intellectual stimulation or (creative encouragement): intellectual stimulation expresses the leader's to challenge the current situation, through suggesting new ideas and encouraging workers to creatively solve problems and motivate them to adopt new ways in work, solve old problems with new perspectives that go along with global developments, and that leads into workers self-trust in developing themselves (Al - Swidi, 2012, p.p 136 - 137).

4. Empowerment: empowerment is an essential behavior for the transformational leader. The main idea of empowerment is that the power of making decisions delegated to the front rows so they can appropriately respond to community requests, needs and problems (Al - Gazali, 2012, p.31).

5. Individual corporate body: This feature refers to the leader's behavior that shows interest and care for his subordinates individually through achieving their comfort and luxury at work. An individual corporate body has an inspiring motive for the leader connecting to the future goals of the organization which are looked at as a challenge for business and personal goals, subordinates are motivated and inspired to achieve them (Ismail et al, 2010, p.96).

Finally, the Kotter model (Kotter, 1998) is one of the most important models in transitioning educational institutions into the transformational leadership model and this model has eight basic steps and they are:

1. To feel the urgency of shifting into the transformational leadership.

2. To create a strong alliance to support shifting into transformational leadership.

3. To set a vision, mission and aims for the organization.

4. All the participants have a clear idea of the vision.

5. Empower others to achieve the vision.

6. Provide an empowerment environment. 
7. To put a short - term plan to do the change.

8. To establish improvements and to reinforce the desire for change.

Kotter also adds that any changing program requires from the administrator to be motivated constantly from the beginning till the end and to institutionalize the new approach. At this stage we must make sure that the new approaches are deeply rooted in the institutional culture.

Based on the above, despite the importance of this theory nevertheless it has some important weaknesses. For example, the theory still indicates that the leader must have high personality traits. He also has to have charisma which automatically makes others follow him, which is in my opinion not enough to judge the personal and professional ethics he has because most of the ethical traits can t be judged normally, plus applying these ethics is very challenging especially in the developing countries. One of the obstacles is the nature of the organizational culture in most organizations in the developing countries which is already rooted in it, and that is originally a negative competitive tribal culture and not a positive integrative culture. So are the hierarchy, severe centralization, the fear of senior management from the loss of power, not wanting to change, caution of the middle management, the workers fear of failure from delegation, lack of motivation, lack of training and self development and administrative distrust ...ect. Despite all these reservations so far, it is in the forefront of revolutionary administrative theories which encourages creativity and innovation by delegating authorities to staff to use their potentials in order to promote their institutions and to leave the old management means despite all the challenges and obstacles.

In this field Al- Qahtani mentioned several challenges that will face the future leadership (transformational leadership) some of them are (Al - Qahtani, 2008, p.18):

1. The globalization of local and national markets, globalization of communication technology and globalization of information.

2. The emergence of organizational management environments characterized with the speed of change and transformation and not depending on one form of organization but it depends on working smarter not harder.

3. The emergence of new organizational trends in institutions and services different from the old organizational trends form, content and function.

4. To demand from subordinates who work in training and human resource management to create a system that provides coexistence and integration between technical and human in new organizations.

The researcher thinks what Al- Qahtani has mentioned is a part of the old future challenges, like competition, etc. It has to be mentioned that there are other challenges. One of these important challenges is the danger of the external environment which threatening the continuation of the organization. What we mean by threat is the environmental danger coming from pollution, the danger of major economics collapsing, also the risk of internal and external wars and conflicts which would lead into emigrating people and the spread of famine and diseases which would lead to more challenges for the transformational leaders in order to keep its sustainability.

\section{Comprehensive Quality}

Higher education is a normal reflection of the social, economic and cultural situation in any country. It is definite that the higher education sector faces lots of challenges and obstacles in different fields including the comprehensive quality application. This age depends on knowledge because of the technological development, in the presence of the internet and social media which helped to exchange knowledge and information easily, this led the higher education institutions to start following complete and comprehensive programs aligned to this age requirements.

\subsection{The Concept of Comprehensive Quality:}

There are many definitions for comprehensive quality. For example, according to (Stevenson, 2007, p.52) comprehensive quality is "a philosophy that takes notice of all workers participating in the production process, decisions taken and paying attention to the internal and external consumer which is the essence of the process". However, concerning this concept, most of the researchers and writers didn't agree with this definition. (Kotler and Dubois, 2006, p.18) defined comprehensive quality as "the effort that the organization makes to constantly improve its products, services, and procedures". (Thunks, 1995, p.32) said that it is "the commitment of the senior management of the organization and its employees to rationalize the business to be able to achieve the customers' needs, desires, and expectations and more". As for (Ciampa, 1992, p.43) he sees that there are three entries to define comprehensive quality: The first entry focuses on the satisfaction of the customer. It defines comprehensive quality as "The participation and commitment of management and staff in rationalizing work and providing the customers' expectations and more". The second entry focuses on the final results represented in error prevention, the continuous improvement of work and products, solving problems quickly and flexibly. And the third entry focuses on the quality tools and instruments including statistical tools and structural means and 
others. The comprehensive quality management is one of the management concepts that received attention for its success in different fields, as it made a huge change in the management philosophy, ideas, principles, and advanced modern systems to achieve the desired aims for any organization. Although there are many definitions for comprehensive quality and different opinions of researchers and specialists from one to another and from time to time, there is a variety of names and descriptions of comprehensive quality management, between new entries, organizational culture, modern philosophy, system, method, and a new administrative style... etc.

Some specialists and researchers see that the concept of comprehensive quality can be clarified by separating between its three elements: (management - quality - comprehensive). Management means developing and maintaining the possibility of the organization to continuously improve quality. Management starts with higher management and ends with staff. As for quality, its meeting and exceeding the beneficiary`s requirements or avoiding defects and shortcomings from the early stages of the process to satisfy the beneficiary. Quality includes product and service quality, quality of social responsibility and the price-quality ... etc. As for the comprehensive, it means to look for quality in any form of work starting from knowing the beneficiary needs and ending with evaluating his satisfaction with the product or service provided to him ...ect (Al-Anini\& others, 2002, p.29) also (Quality, 2010, p.23).

As a researcher, I see that the concept of comprehensive quality management can be clarified by clarifying its elements and not separating quality and comprehensive, so it would become (management, comprehensive quality). Management means developing and maintaining the sustainability of the organization, and what we mean by management that it starts with higher management and ends with staff. As for comprehensive quality, in my opinion, we can not separate quality and comprehensive - as there is no partial quality or comprehensive quality. If quality was fragmented it will lose its aim. Therefore, comprehensive quality means "Integrated operation or system between management and staff (all in his field) which depends on the efficiency and effectiveness in the inputs, processes, and outputs of any organization.

Based on the above, we can conclude that comprehensive quality definition is about its outputs which must meet the customers' wishes and aspirations. To meet these needs the organizational management has to take into consideration the principles and basics of comprehensive quality and provide time, effort and money to accomplish that.

\subsection{The Principles of Comprehensive Quality Management:}

These principles are considered the appropriate atmosphere to apply a modern administrative input where organizations can face the modern market requirements. As the traditional management is not common in the time of rapid environmental changes, fierce competition and organizations race to gain the largest market share and to win customer satisfaction. So they headed towards comprehensive quality management in order to sustain, grow, achieve customers, satisfaction and provide service for them and then achieve community service. Comprehensive quality management includes a group of basics that must be focused on to shift the organization from traditional management to comprehensive quality management and these principles (basics) are: (Al-Khatib, 2008, p.57)

1. The commitment of senior management

2. Continuous improvement

3. Training and development

4. To focusing on customers

5. Making decisions based on facts

6. The participation of workers.

It is worth mentioning that the researchers and writers' opinions are divergent about determining the principles or foundations of comprehensive quality management. Each has his own opinion.

\subsection{The Standards of Comprehensive Quality in Education:}

1. The quality of curricula and University courses and the extent of review and improvement annually or when it is needed

2. The quality of infrastructure in the educational sector and the efficiency of the faculty members

3. The best use of human and financial resources

4. Upgrading the students level in the physical, mental, social, psychological and spiritual aspects

5. To promote community service based on trust and cooperation between educational institutions and society

6. To promote teamwork between workers in the organization, according to the principle of interdependence and integration

7. Practical application in the human development fields away from theoretical words only 


\subsection{The Importance of Comprehensive Quality}

Paying attention to quality is very old it as old as human existence, as quality was his goal in every aspect of his life. However, taking interest in quality from a scientific point of view started in the early 1920s, by the contributions of the engineer Frederick Tyler and his study for time and motion. Since that time, quality has become the center of attention for many researchers (Khudair, 2002, p.23). In this age, comprehensive quality has a strategic importance on the local and national level and it was reinforced since the early 1950s.For example, in 1950 Japan clarified that comprehensive quality is the main goal in building economy, improving productivity and excellence in the market, and therefore having the competitive place that Japan aspires to in national markets and it did. This doesn't mean that quality is limited only to the economic field but also it includes different sectors and public and private institutions. For example, University institutions can use these aspects in order to do their best, and to achieve quality in education, they have to do the following ( $\mathrm{Al}$ - Samurai, 2007, p.303):

1. Reliability: It means that the University must prepare individuals scientifically and professionally in time without delay

2. Efficiency: It means the ability to graduate highly qualified individuals for the labor market

3. Response: The ability to make its workers give the best services

4. Communicate: Parents, students, and bosses know about what the universities are doing now and what are they inspiring to achieve

5. Security: To provide the freedom of speech at University, the academic freedom in teaching and research without any concerns, to allow showing ideas, works and to bravely suggest new ideas as long as they are by the law and is for the common good.

To comment on the above, as a researcher, applying the principles of comprehensive quality in any field and especially in higher education can't be done unless there is a solid base for this application represented in society's culture and values, the extent of its belief in pluralism and democracy, the extent of its provision of freedoms, and the most importuning is the nature of this society and its prevailing policies as a productive or consumer society. If it's a productive community that means it uses policies to support scientific production and research, attract and encourage competencies, and that means it must adopt the principles and values of comprehensive quality to do business efficiently and accurately according to a comprehensive outlook that takes in consideration the interest of individuals and community.

\subsection{The Benefits of Implementing a Comprehensive Quality Management system in higher education} Comprehensive quality can be achieved in education only through establishing the proper intellectual curriculum that the educational process uses. The curricula add the sciences and knowledge that the students receive, ethical values system, human relation system and advanced means of communication and other necessities which make the educational environment fun and attractive to students. Therefore, applying comprehensive quality has many benefits, some of them are:

1. Providing a clear vision, mission, and overall objectives for the institution.

2. The existence of a strategic plan for the institution and operational plans emanating from it for all departments and sections.

3. Implementing a clear, specific, comprehensive, integrated, scientific and stable structure for the educational institution.

4. Providing a clear and specific process manual to achieve quality standards.

5. Defining clear and specific roles in the administrative system of educational institutions.

6. Encouraging scientific research and promoting academic and intellectual freedoms.

7. The comprehensive quality management system gives the institution more respect and appreciation at the local and international recognition.

8. Achieving the beneficiaries' satisfaction (students, parents, teachers, bosses, and society).

9. Achieving a high level of performance for all administrators and employees in the educational institutions.

10. Improving the educational process and its outputs continuously.

\subsection{Previous Studies}

\subsubsection{Arabic Studies:}

The study of (Badah, 2006) titled The degree of Applicability of Comprehensive Quality Management Principles in Jordanian Universities.

The study aimed to know the degree of applicability of comprehensive quality management principles in the Jordanian universities. The study relied on ten areas to examine and they are: (leadership, the mission of the University, organizational culture, information computing, and analysis system, strategic planning, human resource management, training, incentives, participation in decision making, operation management, continuous improvement, customers satisfaction and feedback). The researcher used the descriptive method, and a specific 
questionnaire was designed for this purpose, which was built to include the previous ten areas of comprehensive quality. The study concluded that the possibility of applying the principles of comprehensive quality came largely in Jordanian universities.

The study of (Al- Ka'ke, 2007) titled as A Proposal for the Application of Administrative Quality at Al Riyadh University for Girls

The study amid to suggest a proposal for the application of administrative quality in Riyadh University for Girls in KSA, by identifying the professional preparation of administrations and their level of performance. The researcher used the descriptive method. The data were collected by a questionnaire designed specifically for this purpose. The study concluded several results and they are: training is one of the factors that help in implementing comprehensive quality, information system also helps to exchange information and not conflicting with tasks.

The study of (Al - Misri, 2007) titled Developing the Administrative Performance of the Heads of Academic Departments in the Palestinian Universities in Light of the Principles of TQM

The study amid to identify the level of administrative performance of the heads of academic departments in the Palestinian universities in the light of the principles of TQM.From the point of view of the lecturers, they identify the obstacles facing the heads of academic departments in the application of the principles of comprehensive quality in the performance of their administrative work. The researcher used the descriptiveanalytical method using a questionnaire to collect data. The study concluded several results and the most important are: the administrative performance of the heads of the academic departments by the principles of comprehensive quality was high; it also showed a medium degree of obstacles faced by the heads of academic departments when applying the principles of comprehensive quality.

The study of Harb (2010) titled as Administrative Development of University Leaders in Egypt - in Light of Some Foreign Experiences

The study aimed to develop a proposed concept that contributes to activating the administrative development of University leaders in Egypt - in light of some foreign experiences. The study community included heads of department councils, agents and deans of faculties at Zagazig University. The researcher used the descriptive method. The study concluded several results and they are:There are deficiencies in the project of developing the administrative skills and the capabilities of the University leaders. There are weak training programs for leaders and lack of focus on modern management methods, in addition to being limited to the diagnosis of reality without a vision of the future.

The study of Al-Dossary (2016) titled as Strategic Management of Human Resources and its Role in Preparing Future Leaders in Security and Civil Organizations, KSA.

The study amid to identify the reality of the application of strategic management of human resources and the reality of the preparation of future leaders in both the General Directorate of Civil Defense and the Saudi Credit \& Saving Bank, and the obstacles that may hinder the strategic management of human resources from the preparation of future leaders from the perspective of respondents, and to find out if there is a statistically significant relationship between the application of strategic management of human resources and the preparation of future leaders in the General Directorate of Civil Defense and the Saudi Credit \& Saving Bank. The researcher used the descriptive-analytical method using a questionnaire to collect data about the study community. The study concluded several results and they are: The members of the study at General Directorate of Civil Defense acknowledged that the strategic management of human resources is applied in their directorate to a great extent. As for the Saudi Bank, strategic management is applied little. In regards to the preparation of future leaders, respondents from the two institutions acknowledged that the work to prepare these leaders is done to a small degree.

\subsection{Foreign Studies}

The study of (Russell, 2002) titled as: "Academic Staff Perception of Administrative Quality at Australian Universities"

The study aimed to measure the administrative quality at the Australian Universities, through a measure based on a pattern of academic developments related to the management of universities. The perceptions of the academic authority for administrative quality consists of a system of preliminary concepts defined from the operational aspects and they are: administrative contact, providing administrative materials, reliable advice, providing feedback on administrative changes, the emphasis and the ability to share ideas from others, linking the gentleness of ethics \& trust and the link between individual and understanding.

The administrative quality offered by universities in Australia is tested by the Australian Universities Quality Assurance Agency. Quality is measured by a quality measure used in business and has been reviewed and adopted as a quality measure for Australian Universities too.

The study of (Wiklund, 2003) titled as: "Embedding Quality: The Challenges For Higher Education" The study aimed to find out the opinions of a sample of managers and academics in British higher education 
institutions, about the constraints that pose a challenge associated with quality inclusion. The study was conducted according to the descriptive-analytical method using a questionnaire to collect data. The study has reached several results, some of them are: the application of comprehensive quality needs to be consistent with the culture and structure of the organization, to ensure the success of quality, it is necessary to meet the different needs and concerns of employees.

The study of (Choon, 2008) titled as: "Quality Assurance in Education: An International Perspective" The study aimed to identify the level of understanding of quality assurance at Australian and Malaysian universities to highlight the dynamics of quality assurance and the implementation of public policies within institutions. The study was conducted according to the descriptive-analytical method using a questionnaire to collect data from one of the Australian and Malaysian universities. The study has reached several results, some of them are: There were gaps in the application of quality assurance in the Malaysian universities, the respondents' opinions in both universities agreed that the senior management in each University bears the overall responsibilities for quality management.

\section{Comments on the Previous Studies}

My study agreed with the study of (Badah, 2006), (Al- Ka'ke, 2007), (Wiklund, 2003) and the study of (Choon,2008). They all talk about quality in education and the challenges that face the implementation of comprehensive quality. However, my study differed from all the previous studies by relying on the theoretical literature and internal sources from the University. All previous studies used the questionnaire as a tool to collect data and information. What distinguishes this study from previous studies is that it is the first to address the issue of quality at Al-Istiqlal University by linking it to the transformational leadership. It also examines the difficulties, challenges or obstacles facing this leadership in its role in applying the principles and standards of comprehensive quality, and the available opportunities to overcome the obstacles to the application of quality.

\section{The Questions of the Study}

Comprehensive quality is between challenges and opportunities. The source is the (University strategic plans and the University self - assessment program 2018)

University Administration (leadership)

The administration of $\mathrm{Al}$ - Istiqlal University ( leadership) is represented by its board of trustees and its president Major General Dr. Tawfiq Tirawi, as well as its president. The councils of former and current deans have the characteristics of transformational leaders in terms of exemplary influence, creative encouragement and empowerment of subordinates, attention and care of staff.They also have a future vision that drives them to manage the University according to the latest management theories, in order to apply the principles and standards of comprehensive quality in various academic, security and administrative University areas, in light of the available possibilities despite the difficulties and obstacles they face.

The University belongs to the Palestinian presidency. President Mahmoud Abbas is the supreme president of the University. Major General Dr. Tawfiq Tirawi heads its board of trustees, while its board of trustees is composed of the best leaders who have a long history in struggle and making sacrifices for the sake of homeland, as well as the academic and scientific competencies recognized in various fields of science. The University's leadership continuously encourages providing an organizational culture characterized by participation, dialogue, motivation and promoting roles and complementarity in the work. It also works to set an example for employees in the performance of their work. It encourages love, tolerance, academic, and personal freedom within the limits of regulations, laws, and codes of ethical conduct. The chairman of the board of trustees and the University presidency also meet periodically with all the staff to inform them of the latest developments and exchange views with them and listen to complaints and suggestions of employees. They instruct those concerned to solve problems and overcome difficulties.

\section{Administrative Field}

The University's president, deputies, assistants, and deans have scientific and administrative competences as well as the directors of departments and head of academic and administrative departments work hard to promote participations in decision - making and delegation of authorities. Therefore, the University has developed an administrative structure that ensures horizontal and vertical communication between all its components. The University was also keen to form the necessary councils and committees to do the academic and administrative work, even though the University has (645) employees. The University's departments have also developed strategic plans since its inception and are periodically seeking to review and update them according to feedback and according to the rapid changes that occur in the internal and external environments. The University also evaluated itself in the last year (2018) based on the Quality Standards Manual for Quality Assurance, issued by the Federation of Arab Universities in Amman in (2010). Since its inception, the University has been under the supervision of state civil and security institutions as well as civil society institutions. The University continuously strives to develop the administrative field but still lacks some procedural reference evidence for work. It also doesn't provide its employees with private health insurance (government health insurance is 
available), no nursery is available for children (even though $21 \%$ of employees are women). Also there is no staff housing even though, the employees come from all over the West Bank provinces, which are cut off by the Israeli military roadblocks, which hinder and make it difficult for staff to go from and to the University.

\section{Academic Field (faculty, courses, and students)}

In the academic field, the number of University students for the academic year 2018/2019 reached 1482 students, females constitute $20 \%$ of them. The number of faculty members is 108 teachers, including 82 males and 26 females. They are distributed on scientific ranks (4 professors, 9 as an associate professor, 59 as assistant professor) and the rest is distributed between lecturer and research and teaching assistant. These numbers of scientific ranks are few (professor and associate professor). The University needs to increase these ranks by opening the door for promotions for the faculty members who hold the rank of (assistant professor). The University also has five colleges (Graduate Studies and Scientific Research, Faculty of Administrative Sciences, Faculty of Humanities, School of Law and College of Intermediate Diploma). It offers one master's program, nine undergraduate programs, and three diploma programs, in addition to the Institute of Training and Development, which offers five professional programs in security sciences. The University also publishes a periodical scientific journal. The University graduated from its inception in (2003) to (2018) six cohorts of students numbered (1178) students , 30\% of them are females. The administration of the University at all its levels (administrative, academic and military) works to achieve its mission of supplying the Palestinian Security Services with officers who are qualified academically, military, security and police, by providing courses (the University doesn't provide the majority of its courses, but it depends on borrowing from other universities and the available books and references of modern science). As for the faculty and training commission, the University seeks to attract the most qualified professors and officers of high ranks for teaching and training. As for the students, the University is keen to attract the best students according to a special criteria and conditions related to high GPA in high school, as well as standards related to height, weight and mental health . However, the participation of students in the evaluation of curricula and teachers is ineffective. The University provides a comfortable study environment for students, including equipped halls, library, training fields, sports halls, and extracurricular activities. Students are also provided with courses, food, clothing, medicine, and overnight accommodation, All of this is almost free as it charges a small fee from students and provides graduates with guaranteed jobs in the Palestinian Security Services.

\section{Infrastructure}

The total area of the University including the area on which buildings and facilities are built is about 350 acres. The green area constitutes approximately $50 \%$ of the area on which buildings and facilities are built. The land owned by the University is considered fertile land, suitable for agriculture, but it is not exploited by the University as required in agriculture such as vegetables and fruits to meet its needs. The University also doesn't use the year-rounded clean (solar energy) in Jericho to generate electricity to meet its needs. The University also does not benefit from sewage water by treating it and using it for irrigation. The University contains buildings for its departments and all its faculties in addition to halls, sports stadiums, training fields, accommodation, kitchen, restaurant, and library... etc.

\section{Social Responsibility}

The University's administration and its employees make every effort to provide services to the local community in compliance with its values and ethics through the participation of faculty and staff each in their respective areas of competence in activities that serve the local community such as lectures, seminars and training courses. In addition to many other activities and networking with community institutions. However, the University`s institutional self - evaluation program for itself demonstrated weakness in community service which was an important indicator for increasing and intensifying activities with the local community.

\section{Challenges (obstacles)}

It is no secret that there are difficult conditions experienced by the Palestinian people, who have been under occupation for more than 50 years. These conditions are necessarily reflected in different aspects of life and various public and private sectors. Like other sectors in the country, the education sector is affected by these obstacles. Unfair agreements with the occupying state have deprived Palestine of taking control over its borders. So experience and academic exchange with Arab countries and friendly countries or bringing in special training equipment is subject to the control and approval of the occupying power. That is on the external level, as for the internal level, the dismemberment of the country with barriers and the apartheid wall, all of this is a hindrance and a challenge to the development of education and the application of standards and principles of comprehensive quality.

The University suffers from its limited market (represented by the Palestinian Security Services) as the University accommodates the number of students according to the needs of the security services, which decreases year after year, in the absence of an independent Palestinian state so far. Consequently, there is a lack of a regular army and security services in sufficient numbers, not to mention the fragmentation of the Palestinian division, and depriving students from communicating with the University and study there. 
The University is also facing a financial constraint in the difficult financial conditions that the country suffers in general (the University receives its budget from the budget of the Palestinian Authority), which impedes the progress and development of the University. Based on all the above and in front of these challenges and obstacles, $\mathrm{Al}$ - Istiqlal University administration finds itself facing another challenge which is the issue of sustainability in light of the current and future circumstances that don't bode for a near breakthrough. The University came with the aim of supplying the Security Services with qualified officers and cadres. This is a small market for the University`s outputs if the occupation continues and the situation continues as it is. Thus, it is a candidate for saturation in the near perspective and this, in turn, represents an important challenge that the University administration seeks to overcome by taking advantage of the available opportunities.

In terms of the application of comprehensive quality in terms of infrastructure, the University needs more material resources to meet the requirements of modern housing for employees as the University staff come from all governorates and who are suffering from the barriers established by the occupation.

The obstacles and challenges that I have mentioned are just a flood of rhetoric that cannot be mentioned here.

\section{Opportunities}

Despite the difficult and compelling circumstances the Palestinians suffer from in general and education sector in particular, the University administration has many opportunities that enable it to stand and overcome the obstacles or challenges it faces in order to apply the comprehensive quality thought these opportunities are few. They can be exploited well if possible, for example, the University has recently established a college for intermediate diploma as well as a master's program in public administration for civilian and military students. Work is underway to provide other programs that contribute to reducing the financial impact on the University. The University has also established a vocational training institute with the aim of providing Security Services with professionally qualified individuals in various professions (mechanics, electricity and water networks...ect) to fill the gap related to the shortage of professionally qualified security forces. Through its vision, the University administration seeks to overcome the difficulties and obstacles through working together with friendly Arab and foreign universities to provide the necessary training and expertise for University cadres and graduates. In the future, the University may adopt the same approach as some similar universities (Mu'tah University in Jordan, for example) which is the addition of another section in the University devoted to civilians only and giving academic degrees in various specialties.

\section{Conclusions and recommendations}

Referring to the theoretical literature and internal resources at the University, the study reached the following results:

1. Al- Istiqlal University has transformational leadership that believes in employee participation and motivation to improve performance.

2. The University administration applies as far as possible the principles and standards of comprehensive quality according to its special circumstances.

3. The University self - assessed itself in 2018 with a score of $66 \%$, with weaknesses - for example - in curricula and social responsibility.

4. The University has financial resources (from the Authority`s budget) and it manages them with integrity and transparency through the financial control system.

5. The University has a strategic plan that is constantly reviewed and emanates from its operational plans for its various components.

6. The University has clear rules, regulations that define the relationship between its various components by the functional and ethical code of conduct.

7. The University administration has a written and public vision for the future that aims to overcome obstacles by taking advantage of the available opportunities.

8. The University doesn't use clean energy (solar energy) enough, as more than $80 \%$ of the days of the year there is sunshine in the city of Jericho.

9. The University doesn't make good use of the land it owns to provide its needs of vegetables and fruits.

10. The University`s investment in the field of scientific research is low compared to other universities, which reflects weakness in the scientific production of its cadres and students

Based on the results of the previous study, I make the following recommendations:

1. Enhancing the role of transformational leadership through more meetings with various University cadres and continuing the approach of granting more delegation of authority and powers to employees without prejudice to the cohesion of the institute.

2. To continue striving to apply the principles and standards of comprehensive quality in various areas of the University.

3. To continue the self - evaluation approach periodically, fairly and transparently and utilizing the 
outputs of this evaluation to address weaknesses by taking advantage of available opportunities and strengthening strengths.

4. The need to make use of clean energy (solar energy) to generate electricity for various uses, which reduces the cost of buying it.

5. Utilize the fertile land owned by the University to grow vegetables and fruits for self - sufficiency at least.

6. Recycling (purification) of wastewater for irrigation of crops, especially ornamental trees.

7. Working to provide an integrated University city, which at least provides University accommodation for University staff and nursery for their children, as women represent a good percentage of the University staff.

8. To provide private health insurance for employees and their families.

9. To strengthen and develop the relationship with the local community to ensure the University`s commitment to its social responsibility towards the local community.

10. Investing more in supporting and encouraging scientific research to improve the level of research at the University

\section{References}

Arabic references

- Al - Dossary, M. (2016), Strategic Management and its role in preparing future leaders in security and civil organizations, unpublished Doctoral thesis, Naif Arab University, Saudi

- Al - Kaak, S. (2007) A proposed concept for the application of administrative quality at Riyadh University for Girls in Saudi Arabia, Journal of Educational Science, the second issue.

- Al - Shamaa, K., Hamoud, K. (2000) Organization theory, first edition,Dar Al - Maysara for Distribution and Printing, Iraq

- Al- Ghamdi, S. (2001) Transformational leadership in Saudi Universities: The extent of their practice and possession of their characteristics by academic leaders, A field study, unpublished doctoral thesis, Umm Al -Qura University, Saudi Arabia.

- Al-Khatib, S. (2008), Comprehensive Quality Management - Contemporary Entrance, Al - Mortada Publishing House, Iraq.

- Almisiri, M. W. (2007) Developing the administrative performance of the heads of the academic departments in the Palestinian universities in light of the principles of comprehensive quality management, unpublished Master Thesis, Islamic University, Palestine

- Al-Samarayy, M. (2007) Comprehensive Quality Management in the production and service sector, first edition, Dar Jarida for Publishing \& Distribution, Jordan

- Ani, K. I. et al (2002) Comprehensive Quality Management and ISO Requirements, Blond press, first edition, Iraq

- Badshah, A. (2006) A suggested model for comprehensive quality management in Jordanian public universities, Journal of the Federation of Arab Universities, No.46.

- Bernoulli, S. (2010),Business Administration, first edition, Al - Wael for Publishing \& Distribution, Jordan.

- Ghazali, A. (2012) The impact of transformational leadership on the effectiveness of decision making, master thesis, business school, Middle East University, Jordan

- Gulab, I. (2011), Organizational Behavior Management in the Age of Change. Safaa Publishing \& Distribution House, Jordan.

- Harb, I. (2010) Administrative development of University leaders in Egypt in light of some foreign experiences, unpublished Master thesis, Zagazig University, Egypt

- Issawi, A. (2008) Strategy of military leadership from a psychological perspective, first edition, Dar Alfikr Al Jamieiu, Egypt

- Juduh, M. (2010) Comprehensive Quality Management -Concepts and applications - fifth edition, Wael Publishing House, Jordan

- Katzenbach, John, localization, Shammout Mohammed Hassan (2005) distinctive performance "compatibility between the mind and heart", second edition, Obeikan Library for Publishing \& Distribution, Jordan.

- Khudair, K. (2002) Comprehensive Quality Management, Dar Al - Maysara for Publishing and Distribution, Jordan.

- Mohammad, S. (2010) Leadership and decision-making methods, first edition, ATRAK for Printing, Publishing and Distribution, Egypt

- Qahtani, S. (2008) Management Leadership - Transformation towards the global leadership model, King Fahd National Library, second edition, Riyadh 


\section{Internal sources of the University}

Strategic plans for the University, including (complementary strategic plan 2017 - 2020) for Al - Istiqlal University. Al - Istiqlal University self - assessment program (2018) according to the manual of standards and weights for quantitative and qualitative indicators for quality assurance and accreditation of the Arab Universities of the Federation issued in 2010 in Amman, Jordan

\section{Foreign references:}

- Al - Swidi, A. K., Nawawi, M. K.\& Al-Hassam, A. (2012), Is the Relationship between Employee's Psychological Empowerment and Employee`s 67 - Job Satisfaction Contingent on the Transformational Leadership, A Study on the Yemeni Islamic Banks, Asian Social Science Vol. 8, No. 10.

- Bass, B.M. (1985), Leadership, Good, Better, Best, Organizational Dynamics, winter, Elsevier journals.

- Burns, J. (1978) Leadership, New York, Harper.

- Choon, F. (2008): Quality Assurance in Education: An International Perspective, Journal Articles; Reports, Research, v16 n2.

- Ciampa, D. (1992) Comprehensive quality: a user`s guide for implementation, Reading, MA Addison - Wesley.

- Goodwin, V., Whittington, J. \& Murray, B. (2011), Moderator or Mediator Examining the Role of Trust in the Transformational Leadership Paradigm, Journal of Managerial Issues, Vol. XXII Number 4.

- Ismail, A. Mohamad, M., \& et al (2010), "Transformational and Transactional Leadership Styles", Theoretical and Applied Economics, Volume Xvi), No. 6(547).

- Kotter J. P. (1998), Cultures and coalitions, in Gibson, R, - rethinking the future, Nicholas Brealey, London.

- Kotler P., Keller,K., Dubois, B., Mancau, D. (2006) Marketing Management. Pearson Education.

- Niekerk, M., Maria, V. (2005)" Transformational Leadership at a Higher Education Institution", Master of Arts, University of South Africa.

- Russell, F. (2002): Academic staff perceptions of administrative quality at universities, Journal of Educational Administration, Volume 40.

- Sani, A.\& Maharani, V., (2012), The impacts of Transformational Leadership and Organizational Commitment on Job Performance with the among Lecturers of faculty in the Islamic Maulana Malik Ibrahim Malang University: the mediating effects of Organizational Citizenship Behavior, International, Journal of Academic Research, Vol. 4. No.4.

- Stevenson, W. (2007) “Operational Management", $8^{\text {th }}$ ed, McGraw - Hill.

- Thunks, R, Fast Track to quality, Mc Graw - Hill, Inc., New York, 1995.

- Wiklund, H., et al (2003): Embedding Quality: The Challenges for Higher Education, Quality Assurance in Education, Vol. 12,Issue.4 